\title{
Histamine and Thrombin Modulate Endothelial Focal Adhesion Through Centripetal and Centrifugal Forces
}

\author{
Alan B. Moy, ${ }^{\star}$ Jeff Van Engelenhoven, ${ }^{\star}$ James Bodmer, ${ }^{\star}$ Jay Kamath, ${ }^{\star}$ Charles Keese, ${ }^{\ddagger}$ Ivar Giaever, ${ }^{\ddagger}$ S. Shasby, \\ and D. Michael Shasby* \\ *Department of Internal Medicine, University of Iowa College of Medicine and the Veterans Administration Hospital, Iowa City, Iowa, \\ 52242; and ${ }^{\ddagger}$ Department of Biology and Physics, School of Science, Rensselaer Polytechnic Institute, Troy, New York 12180
}

\begin{abstract}
We examined the contribution of actin-myosin contraction to the modulation of human umbilical vein endothelial cell focal adhesion caused by histamine and thrombin. Focal adhesion was measured as the electrical resistance across a cultured monolayer grown on a microelectrode. Actin-myosin contraction was measured as isometric tension of cultured monolayers grown on a collagen gel. Histamine immediately decreased electrical resistance but returned to basal levels within 3-5 min. Histamine did not increase isometric tension. Thrombin also immediately decreased electrical resistance, but, however, resistance did not return to basal levels for 40-60 min. Thrombin also increased isometric tension. ML-7, an inhibitor of myosin light chain kinase, prevented increases in myosin light chain phosphorylation and increases in tension development in cells exposed to thrombin. ML-7 did not prevent a decline in electrical resistance in cells exposed to thrombin. Instead, ML-7 restored the electrical resistance to basal levels in a shorter period of time $(20 \mathrm{~min})$ than cells exposed to thrombin alone. Also, histamine subsequently increased electrical resistance to above basal levels, and thrombin initiated an increase in resistance during the time of peak tension development. Hence, histamine and thrombin modulate endothelial cell focal adhesion through centripetal and centrifugal forces. (J. Clin. Invest. 1996. 97:1020-1027.) Key words: endothelium • cell adhesion - isometric contraction • histamine • thrombin
\end{abstract}

\section{Introduction}

Edemagenic agents disrupt endothelial focal adhesion between cell-cell and between cell-matrix contact sites (1-5). The mechanism that regulates this phenomena is not precisely understood. Several lines of evidence suggest that focal adhesion is regulated by an opposing interaction between centrifugal tethering forces applied to cell-cell and cell-matrix sites that maintain cell adhesion, and centripetal forces, mediated, in part, by actin-myosin tension (1, 6-10). Based on this paradigm, centripetal actin-myosin contraction could disrupt cen-

Address correspondence to Alan B. Moy, Department of Internal Medicine, SW 34 F GH, University of Iowa College of Medicine, Iowa City, IA 52242. Phone: 319-356-3634; FAX: 319-353-6406; E-mail: amoy@blue.weeg.uiowa.edu

Received for publication 28 July 1995 and accepted in revised form 30 November 1995.

The Journal of Clinical Investigation

Volume 97, Number 4, February 1996, 1020-1027 trifugal tethering forces and cause a loss of focal adhesion. Alternatively, a resting centripetal tension could effect centripetal movement of the cell cortex, if centrifugal tethering were disrupted.

Several pieces of data support these hypothesis. Pitelka et al. observed centripetal movement of the cortex of epithelial cells when centrifugal tethering was disrupted by chelation of extracellular calcium (11). Kolodney and Wysolmerski observed that thrombin increased centripetal isometric tension in cultured human umbilical vein endothelial cells (HUVEC) ${ }^{1}$ (6). More recently we found that inhibition of myosin light chain phosphorylation reduced centripetal movement of endothelial cells after exposure to histamine or after chelation of extracellular calcium (8).

In this manuscript, we investigated the precise role of centripetal actin-myosin tension on changes in endothelial cell focal adhesion by asking: (a) is centripetal isometric tension development in HUVEC in response to histamine and thrombin dependent on myosin light chain kinase (MLCK)-dependent increases in $20-\mathrm{kD}$ myosin light chain $\left(\mathrm{MLC}_{20}\right)$ phosphorylation? and $(b)$ are changes in focal adhesion in response to histamine and thrombin dependent on increases in MLCKdependent centripetal tension?

\section{Methods}

Materials. Tissue culture supplies were obtained from the Cancer Center, University of Iowa, Iowa City, IA. FBS was obtained from Hyclone Laboratories, Inc. (Logan, UT). Histamine and cytochalasin D were obtained from Sigma Chemical Co. (St. Louis, MO). Topical bovine thrombin was obtained from the University of Iowa Hospital and Clinic Pharmacy (Iowa City, IA). Vitrogen collagen (Type 1, bovine dermal collagen) was obtained from Celtrix Pharmaceuticals Inc. (Santa Clara, CA). ML-7 was obtained from Calbiochem Corp. (La Jolla, CA). All other chemicals were reagent grade.

Cell culturing. Cultured HUVEC were prepared by collagenase treatment of freshly obtained human umbilical veins as described (3). Harvested primary cultures designated for cell-adhesion assays were plated on $60-\mathrm{mm}$ tissue culture plates that were coated with $100 \mu \mathrm{g} /$ $\mathrm{ml}$ of fibronectin (Collaborative Research Inc., Bedford, MA). Cells designated for tension experiments were plated on 100-mm fibronectin-coated plastic dishes. Cells designated for phosphorylation and peptide mapping were plated on 25-mm polycarbonate filters coated with fibronectin. Experiments were conducted after cultures reached 2-d postconfluency. All cells were cultured in medium 199 and supplemented with $20 \%$ heat-inactivated FCS, basal medium Eagle vitamins and amino acids, glucose $(5 \mathrm{mM})$, glutamine $(2 \mathrm{mM})$, penicillin $(100 \mathrm{U} / \mathrm{ml})$, and streptomycin $(100 \mu \mathrm{g} / \mathrm{ml})$. Cultures were identified

1. Abbreviations used in this paper: ECIS, electrical cell-substrate impedance sensor; HUVEC, human umbilical vein endothelial cell; $\mathrm{MLC}_{20}, 20-\mathrm{kD}$ myosin light chain; MLCK; myosin light chain kinase; $\mathrm{mP}$, moles of phosphate. 
as endothelial cells by their characteristic uniform morphology, uptake of acetylated LDL, and by indirect immunofluorescent staining for Factor VIII.

Measurement of isometric tension. Isometric tension in cultured endothelial cells was measured using a modification of the technique described by Kolodney and Wysolmerski (6). A mold measuring 25$\mathrm{mm}$ in width $\times 85$ - $\mathrm{mm}$ in length $\times 20$ - $\mathrm{mm}$ in depth was constructed and placed in the center of a $100-\mathrm{mm}$ polymethylpentene petri dish and filled with Sylgard 186 silicone elastomer (Crown Distributing Inc., Bridgeton, MO) and allowed to harden overnight. The molds were removed the next day which created an experimental chamber. Porous polyethylene bars measuring $8 \mathrm{~cm}$ in length $\times 5 \mathrm{~mm}$ in width were cut from 6-mm thick stock sheets (Fisher Scientific Corp., Santa Clara, CA). Strips of velcro were machine sewn to one side of each bar with nylon thread. Polyethylene bars were alcohol treated, boiled in water, and, finally, gas sterilized at room temperature along with the experimental chamber. $5 \mathrm{ml}$ of an unpolymerized collagen mixture (4.6 ml of vitrogen collagen, $6.4 \mathrm{ml}$ of $2 \times$ DME Media [with $10 \%$ FCS and $100 \mathrm{U} / \mathrm{ml}$ penicillin and $100 \mu \mathrm{g} / \mathrm{ml}$ of streptomycin, $2 \mathrm{mM}$ glutamine with basal medium Eagle vitamins and amino acids], $2.0 \mathrm{ml}$ of FCS) was poured between the two polyethylene bars and allowed to polymerize overnight at $37^{\circ} \mathrm{C}$. Stock solutions were maintained at $4^{\circ} \mathrm{C}$ to prevent premature polymerization, and the $\mathrm{pH}$ of the collagen mixture was confirmed at $\sim 7.4$ using $\mathrm{pH}$ paper. The next day, the polymerized gel was then equilibrated for $3 \mathrm{~h}$ with M199 media with $20 \%$ FCS. Afterwards, media was aspirated, and the surface of the collagen was rinsed well with PBS. The collagen matrix was inoculated with $\sim 4.0 \times 10^{6}$ cells after the surface of the membranes were coated with $100 \mu \mathrm{g} / \mathrm{ml}$ of fibronectin for $15 \mathrm{~min}$. Cell were grown in M199 supplemented with $20 \%$ FCS. Tension experiments were conducted after cultures were 2-d postconfluency. For an experiment, one end of a 3.5-in., 25-gauge spinal needle was attached to the midpoint of one polyethylene bar and the other end was attached to an $\mathrm{x}, \mathrm{y}, \mathrm{z}-\mathrm{multiaxis}$ stage manipulator (Medical Instruments, University of Iowa). The end of a second needle was attached to the midpoint of the other polyethylene bar while the other end of the needle was affixed to an isometric force transducer (52-9545; Harvard Apparatus Co., S. Natick, MA). The force transducer was internally recalibrated so that it could measure tension in both the vertical and horizontal axis (Eric LaWhite Co., S. Royalton, VT). The force transducer was interfaced with an analog digital converter board (National Instruments Corp., Austin, TX). Data acquisition was controlled with Lab View Software (National Instruments). High frequency electrical noise was filtered with a low-pass filter (National Instruments). Before each experiment, the transducer was calibrated with a series of weights ranging from 10 to $500 \mathrm{mg}$. The experimental chamber was filled with media so that the collagen-bars floated in order to limit the amount of friction. All measurements were conducted at $37^{\circ} \mathrm{C}$ in humidified $5 \% \mathrm{CO}_{2} / 95 \%$ air atmosphere. Since phosphorylation and cell resistance studies were conducted under non-prestressed conditions, we deliberately measured isometric tension under similar non-prestressed conditions. We used the following protocol to accomplish this. The output from the transducer was monitored for $30 \mathrm{~min}$ without a load to confirm that the force transducer maintained a steady baseline. The transducer was then offset to zero. The collagen matrix was then attached to the transducer. Approximately 5-10 mg of prestress was placed on the collagen gel to ensure that the membrane was sufficiently straightened and all connections were secured. The transducer was offset to $\sim 30-40 \mathrm{mg}$ which represented the approximate amount of constitutive tension. The transducer was monitored for an additional $30 \mathrm{~min}$ to assure that no drift in the baseline occurred. To differentiate a valid increase in isometric tension generated by the cytoskeleton from a nonspecific mechanical deflection of the force transducer, we compared the response of our test agents with a sham response which consisted of a comparable volume of carrier buffer as the test agent. Tension development was considered valid if it could be abolished by $1 \mu \mathrm{g} / \mathrm{ml}$ of cytochalasin D and it exceeded a sham response $(6,12)$. In some experiments tension was normalized to the initial value and expressed as a fraction of the normalized value. Nonspecific tension development generated from the sham response was subtracted from the actual measured tension of each test agent to more accurately reflect the expressed tension for histamine and thrombin. For example, if thrombin increased tension by $50 \%$ and the sham response increased by $10 \%$ at the corresponding time point, then a fraction of 1.4 was reported for thrombin.

Focal adhesion assay. Focal adhesion was measured using the technique previously reported by Keese and Giaever (13-16). In this system, referred to as an electrical cell-substrate resistance sensor (ECIS), the cells were cultured on a small gold electrode $\left(10^{-4} \mathrm{~cm}^{2}\right)$, and culture media was used as the electrolyte, and focal adhesion was measured dynamically by determining the electrical resistance of the monolayer. The total resistance across the monolayer is composed of the resistance between the ventral surface of the cell and the electrode and the resistance between cells (15). Thus, a change in electrical resistance represents a change in cell-cell adhesion and/or cellmatrix adhesion. Change in resistance does not reflect a local change in the conductivity of the media due to the transcellular transport of ions secreted by the endothelium. The constrictive resistance, or the resistance of the surrounding media, contributes to only $\sim 10-15 \%$ of the total resistance of a cell-covered electrode $(15,17)$. For the electrical resistance to decrease by $50 \%$, the endothelium would need to secrete and increase the total amount of ions in the media by three to fivefold. It is very unlikely that the cells could release enough ions to accomplish this.

Electrodes were prepared in a manner similar to that described by Keese and Giaever (13-15). ECIS electrode arrays were fabricated by Applied Biophysics, Inc. (Troy, NY). The completed electrodearray mounts into a holder that makes electrical contact through the gold contact pads and is connected to the ECIS instrumentation. The small electrode and the larger counter electrode $\left(1 \mathrm{~cm}^{2}\right)$ were connected to a phase-sensitive lock-in amplifier (5301A; EG\&G Instruments Corp, Princeton, NJ) with a built in differential preamplifier (5316A; EG\&G Instruments Corp.). A $1 \mathrm{~V}, 4,000 \mathrm{~Hz}$ AC signal was supplied through a 1-M $\Omega$ resistor to approximate a constant-current source. Voltage and phase data were stored and processed with an IBM-compatible computer. The same computer also controlled the output of the amplifier and relay switches to different electrodes. The critical feature of the setup is the surface area of the small electrode. At a surface area of $10^{-4} \mathrm{~cm}^{2}$ and $4,000 \mathrm{~Hz}$, changes in cell resistance are clearly revealed. For experiments, electrodes were coated with $100 \mu \mathrm{g} / \mathrm{ml}$ of fibronectin for $30 \mathrm{~min}$. HUVECs were inoculated on

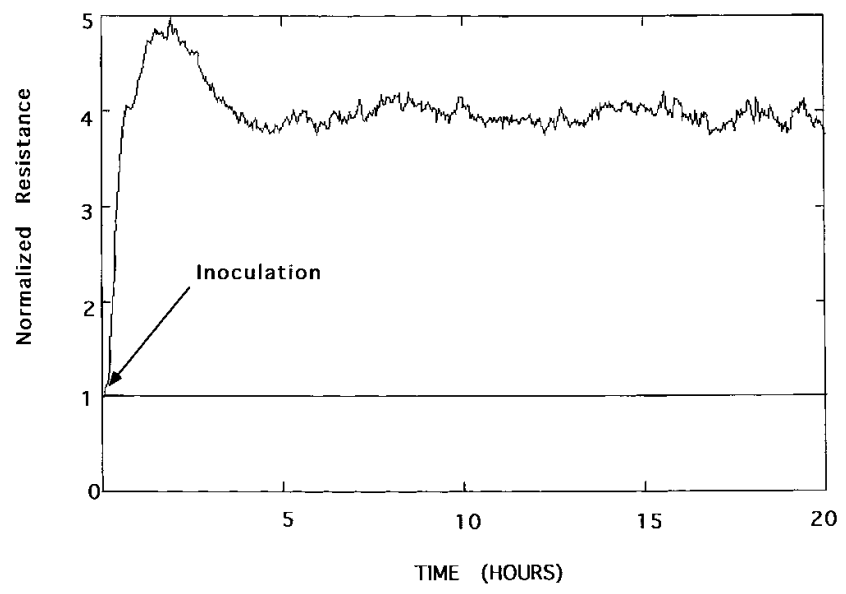

Figure 1. Figure represents the normalized resistance over several hours as a confluent cultured monolayer $\left(10^{5} \mathrm{cell} / \mathrm{cm}^{2}\right)$ was inoculated on the ECIS electrode coated with $100 \mu \mathrm{g} / \mathrm{ml}$ of fibronectin. The inphase voltage is displayed and normalized to the initial value. Tracing is representative of 30 experiments. 
electrodes at a confluent density of $10^{5}$ cells $/ \mathrm{cm}^{2}$. The in-phase voltage (proportional to the resistance) and the out-of-phase voltage (proportional to the capacitance) were measured. Electrical resistance increased immediately after cells attached and covered the electrodes and the resistance achieved a steady state by $24 \mathrm{~h}$ (Fig. 1). By $24 \mathrm{~h}$ the monolayer covering the ECIS electrode achieved confluence when looked at under a microscope, and, thus, experiments were conducted after the electrical resistance achieved a steady state. Experiments were conducted on wells which achieved $>5,000 \mathrm{ohms}$ of steady state resistance. Focal adhesion was expressed by the inphase voltage (proportional to the resistance) which was normalized to the initial voltage and expressed as a fraction of the normalized value.

Measurement of myosin light chain phosphorylation. Identification and quantitation of the phosphorylation of the $20-\mathrm{kD}$ myosin light chain was accomplished by laser densitometry of two-dimensional gels of $\mathrm{MLC}_{20}$ isoforms immunoprecipitated from ${ }^{35} \mathrm{~S}$-labeled cells according to the procedure described by Ludowyke and Adelstein (18) and subsequently modified as we have described (1). Stoichiometry was calculated by determining the relative fraction of phosphorylated isoforms to all isoforms according to the expression: stoichiometry $=$ fraction of monophosphorylated isoform $+2 \times$ fraction of diphosphorylated isoforms.

Phosphorylation of the 20 - and $19.7-\mathrm{kD}$ isoforms were not statistically different, and the average phosphorylation of the two isoforms is reported.

Peptide mapping of tryptic peptide fragments. Generation of twodimensional peptide maps of phosphorylated tryptic peptides were performed in ${ }^{32} \mathrm{P}$-labeled unstimulated cells and cells exposed to thrombin as we previously described (1). In addition, one-dimensional peptide maps were constructed from light chains immunoprecipitated from ${ }^{32} \mathrm{P}$-labeled HUVE cells as described by Daniel and Sellers (19). Briefly, immunoprecipitate was dissolved in SDS sample buffer and separated on an $8-15 \%$ polyacrylamide gradient gel as described (1). The washed, dried gel slices were minced and suspended in $950 \mu \mathrm{l} 100 \mathrm{mM} \mathrm{NH}_{4} \mathrm{CO}_{3}, \mathrm{pH} 8.0$, and digested for $24 \mathrm{~h}$ in $1 \mathrm{mg} / \mathrm{ml}$ TPCK trypsin at $37^{\circ} \mathrm{C}$. Additional trypsin was added for 5 more $\mathrm{h}$. The supernatant was aspirated and lyophilized in a speed vac (Savant Instruments, Inc., Farmingdale, NY). The dried sample was dissolved in $50 \mu \mathrm{l}$ of the $\mathrm{NH}_{4} \mathrm{CO}_{3}$ and applied to the gel in a $2 \times 2 \mathrm{~mm}$ piece of filter paper, as described by Daniel (19).

Samples were electrophoresed on a 0.5 -mm thick $7 \%$ polyacrylamide gel mounted in a Multiphor II Electrophoresis System (Pharmacia LKB Biotechnology Inc., Piscataway, NJ). The gel was preelectrophoresed for $10 \mathrm{~min}$ at $30 \mathrm{~W}, 1,000 \mathrm{~V}$ before addition of the sample. The sample in the filter paper was added to the cathode side, and then the gel was electrophoresed for $1 \mathrm{~h}$ at $1,000 \mathrm{~V}$. The gel was removed and dried and then exposed to x-ray film to develop the autoradiogram. Standards of myosin light chain phosphorylated by myosin light chain kinase were prepared as we have described (1).

Statistical analysis. Data was reported as means \pm standard errors (SE). Comparisons between groups were made using the Student $t$ test. Comparisons between more than two groups were made using ANOVA. Differences were considered significant at the $P \leq 0.05$ level.

\section{Results}

Thrombin mediates $M L C_{20}$ phosphorylation through $M L C K$. To verify that MLCK mediated MLC $_{20}$ phosphorylation in HUVEC in response to thrombin, we examined the peptide map pattern of tryptic fragments of $\mathrm{MLC}_{20}$ phosphorylated under controlled and thrombin-stimulated conditions. Using a two-dimensional peptide map separation technique, (Fig. $2 \mathrm{~A}$ ) control or thrombin stimulated-cells generated a peptide map pattern that was consistent with the two-dimensional peptide map of the in vitro standard for MLCK. Additionally, tryptic
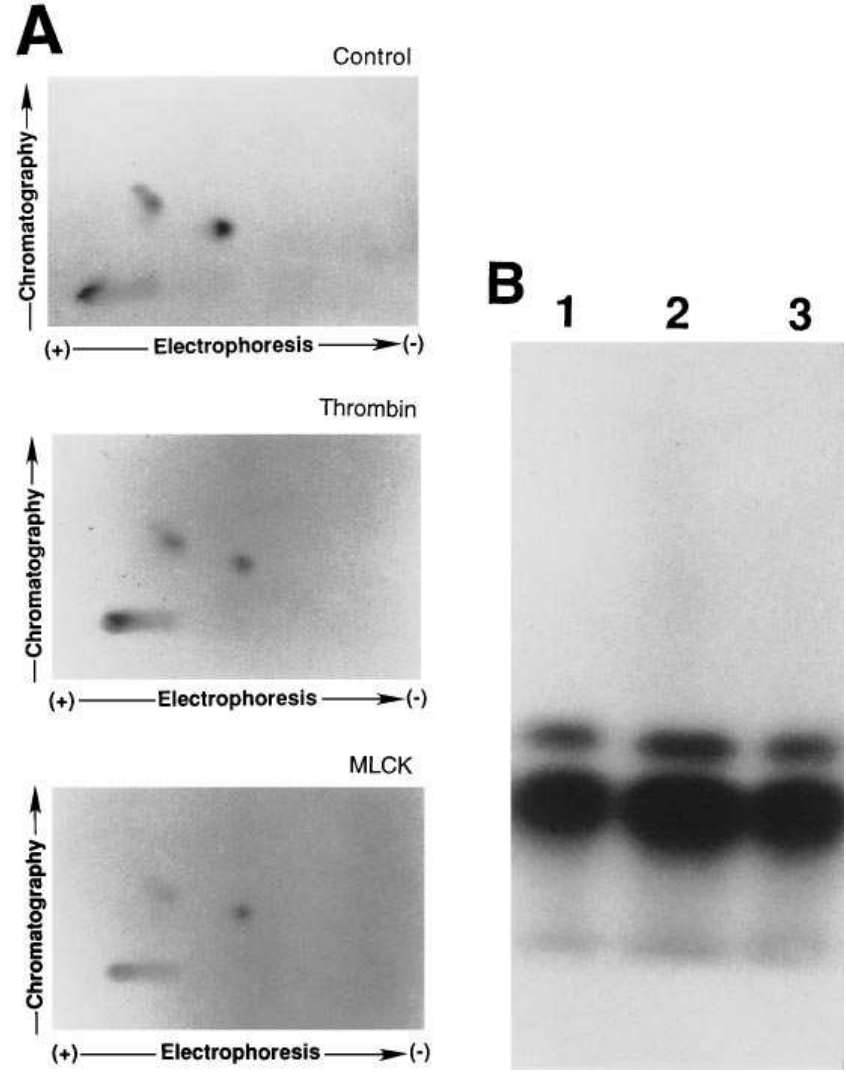

Figure 2. (A) Myosin light chain was isolated by immunoprecipitation of myosin from ${ }^{32} \mathrm{P}$-labeled cultured HUVEC and separated by SDS-PAGE. Light chains were excised, incubated with trypsin, and separated by two-dimensional peptide mapping as described in Methods. Figure represents a composite illustration of peptide maps in controlled cells, in cells exposed to $7 \mathrm{U} / \mathrm{ml}$ of thrombin, and a standard of gizzard myosin light chain phosphorylated in vitro with MLCK. (B) Peptide map based on isoelectric focusing of phosphorylated tryptic fragments. Lane 1 represents a separation of phosphopeptides of controlled cells; lane 2 represents separation of digest in thrombin-stimulated cells; lane 3 represents separation of the MLCK standard. Peptide maps based on both techniques demonstrate that MLCK mediated phosphorylation in response to thrombin.

digests were also separated by a one-dimensional isoelectric focusing technique previously described (Fig. 2 B) (19). The peptide map pattern for control and thrombin stimulated cells was the same as the in vitro standard for MLCK. These results confirm that MLCK mediated light chain phosphorylation in response to thrombin.

The effect of thrombin on isometric tension in cultured endothelial cells. We next confirmed that thrombin increased isometric tension in cultured HUVEC using the technique previously reported by Kolodney and Wysolmerski (6) (Fig. 3). Upon exposure to $7 \mathrm{U} / \mathrm{ml}$ of thrombin, tension increased as early as $30 \mathrm{~s}$ and achieved maximal levels within $8-12 \mathrm{~min}$. The change in isometric tension observed with thrombin exceeded the response observed with the sham, indicating that tension development did not occur because of a nonspecific deflection of the force transducer. Also, the amount of force generated by thrombin was abolished by the subsequent addition of cytochalasin $\mathrm{D}$, suggesting that tension development was mediated through the actin-cytoskeleton. Thrombin also caused 


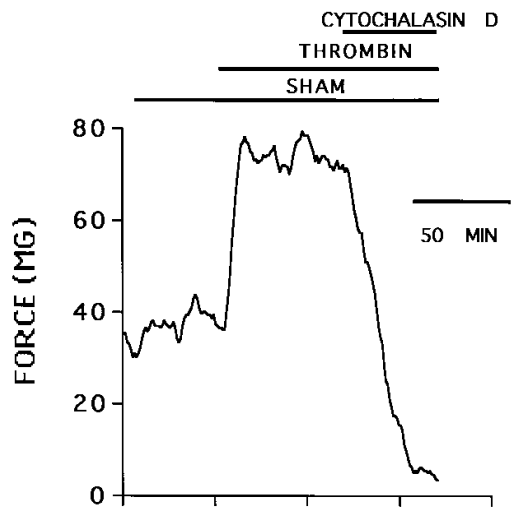

Figure 3. Figure represents the effect of $7 \mathrm{U} /$ $\mathrm{ml}$ of thrombin on isometric tension after exposure to a sham buffer of comparable volume. Subsequent exposure to cytochalasin suggests that tension development was dependent on the actin-cytoskeleton. See text for discussion.

similar increases in isometric tension at doses of $0.1,1.0$, and 7 $\mathrm{U} / \mathrm{ml}$ (Fig. 4). After exposing the monolayer to $0.1 \mathrm{U} / \mathrm{ml}$ of thrombin, there was little to no increment in tension development with the subsequent addition of doses of 1 and $7 \mathrm{U} / \mathrm{ml}$. Doses of $7 \mathrm{U} / \mathrm{ml}$ of thrombin were used in following experiments because it displayed maximal changes in electrical resistance (demonstrated later).

The dependence of tension development on increased $M L C_{20}$ phosphorylation and MLCK. We observed a temporal relationship between $\mathrm{MLC}_{20}$ phosphorylation and isometric tension in cultured HUVEC's in response to thrombin (Fig. 5). Thrombin $(7 \mathrm{U} / \mathrm{ml})$ increased phosphorylation from $0.39 \pm 0.2$ moles of phosphate per mole of light chain $(\mathrm{mP} /$ $\mathrm{mMLC}$ ) to a peak of $0.89 \pm 0.1 \mathrm{mP} / \mathrm{mMLC}$ at $15 \mathrm{~min}$. Phosphorylation subsequently decreased to $0.6 \pm 0.008 \mathrm{mP} / \mathrm{mMLC}$ at 20 min, $0.52 \pm 0.04 \mathrm{~mol}$ at $30 \mathrm{~min}$, and $0.51 \pm 0.02 \mathrm{~mol}$ at $45 \mathrm{~min}$. Changes in isometric tension paralleled changes in $\mathrm{MLC}_{20}$ phosphorylation in response to thrombin. Tension development increased and achieved maximal force generation at 12 min and subsequently decreased to submaximal levels (Fig. 5).

At concentrations of $0.1,1$, and $7 \mathrm{U} / \mathrm{ml}$ thrombin caused similar increases in tension (Fig. 4). These same concentrations increased MLC phosphorylation from $0.41 \pm 0.03 \mathrm{mP} / \mathrm{mMLC}$ to $0.82 \pm 0.05,0.81 \pm 0.04$, and $0.76 \pm 0.03 \mathrm{mP} / \mathrm{MMLC}$ in $10 \mathrm{~min}$, respectively ( $n \geq 7$ for each group).

Thrombin increased tension and phosphorylation by $57.6 \pm$ $6.1 \mathrm{mg}$ and $0.5 \pm 0.09 \mathrm{mP} / \mathrm{mMLC}$, respectfully, within $15 \mathrm{~min}$ (Table I). To determine if tension development in response to thrombin is dependent on MLCK-mediated increases in light

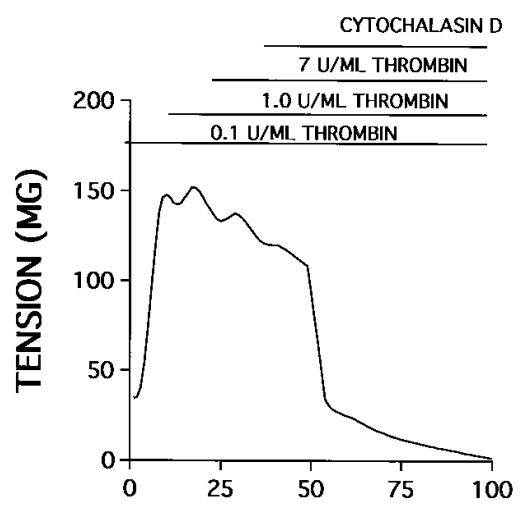

TIME (MIN)

Figure 4. Figure demonstrates the serial doseresponse of thrombin on isometric tension at doses of $0.1 \mathrm{U} / \mathrm{ml}, 1.0$ $\mathrm{U} / \mathrm{ml}$, and $7 \mathrm{U} / \mathrm{ml}$. See text for discussion.

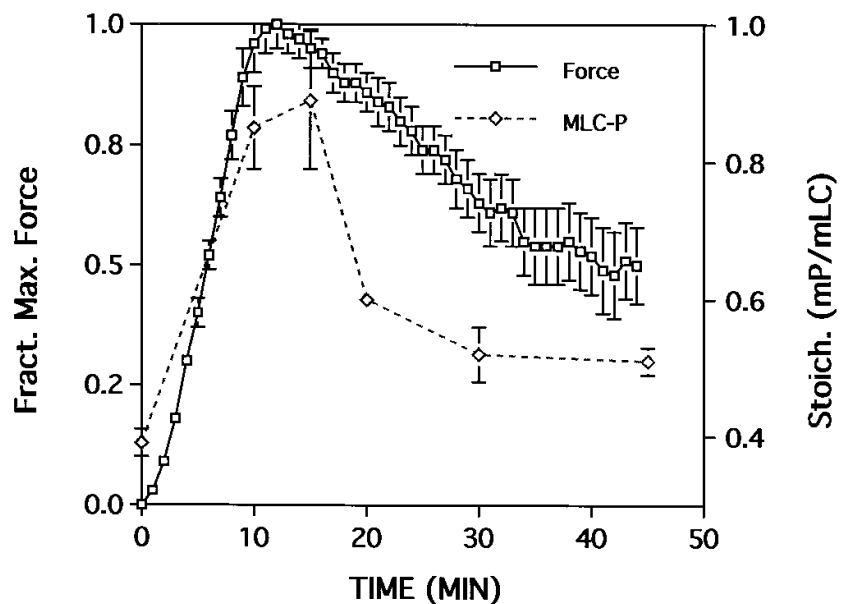

Figure 5. Myosin light chain from cultured HUVEC labeled with ${ }^{35} \mathrm{~S}$-methionine was isolated by immunoprecipitation of myosin and separated by two-dimensional gel electrophoresis and quantitated by laser densitometry as described in Methods. Phosphorylation and tension experiments were executed separately in cells exposed to $7 \mathrm{U} /$ $\mathrm{ml}$ of thrombin. Data are reported as the means \pm SE. Each data point for tension represents an $n=13$ and each data point for phosphorylation represents an $n=3$.

chain phosphorylation, we compared the changes in phosphorylation and tension in cultured HUVEC exposed to thrombin in the presence and absence of ML-7, an inhibitor of MLCK (Table I). $100 \mu \mathrm{M}$ ML-7 alone decreased tension by $18.1 \pm 8$ $\mathrm{mg}$ within $30 \mathrm{~min}$, while phosphorylation decreased by $0.084 \pm 0.04 \mathrm{mP} / \mathrm{mMLC}$ in the same time interval. Additionally, pretreatment with ML-7 prevented an increase in tension and phosphorylation in cells exposed to thrombin. Tension did not change $(+0.37 \pm 1.7 \mathrm{mg}$ from the level established after ML-7 alone), and phosphorylation did not change $(-0.01 \pm 0.03 \mathrm{mP} /$ mMLC) in thrombin-stimulated cells that were pretreated with ML-7.

$10 \mu \mathrm{M}$ histamine increased phosphorylation by $0.22 \pm 0.03$ $\mathrm{mP} / \mathrm{mMLC}$ (achieving an absolute level of $0.44 \pm 0.03 \mathrm{mP} /$ mMLC) within $15 \mathrm{~s}$ but did not significantly increase tension

Table I. Isometric Tension and Stoichiometric Change in Phosphorylation in Cultured HUVECs

\begin{tabular}{lcc}
\hline \multicolumn{1}{c}{ Test agent } & $\Delta$ Tension & $\Delta$ Phosphorylation \\
\hline & $m g$ & $m P / m M L C$ \\
Sham & 0 & $0.0 \pm 0.02$ \\
Thrombin & $57.6 \pm 6.1^{*}$ & $0.5 \pm 0.09^{*}$ \\
ML-7 & $-18.1 \pm 8$ & $-0.084 \pm 0.04$ \\
ML-7-thrombin & $0.37 \pm 1.7^{\ddagger}$ & $-0.01 \pm 0.03^{\ddagger}$ \\
Histamine & $0.59 \pm 1.54^{\ddagger}$ & $0.22 \pm 0.05^{*}$ \\
& & \\
\hline
\end{tabular}

Isometric tension, expressed as the change in force (milligrams) from the sham response, is reported with the stoichiometric change in phosphorylation in cultured HUVEC exposed to sham, $7 \mathrm{U} / \mathrm{ml}$ of thrombin for $15 \mathrm{~min}, 100 \mu \mathrm{M}$ ML-7 for $30 \mathrm{~min}, 100 \mu \mathrm{M}$ ML-7 for $30 \mathrm{~min}$ followed by 15 -min exposure to thrombin, and $10 \mu \mathrm{M}$ histamine for $15 \mathrm{~s}$. Data are reported as the means $\pm \mathrm{SE}$ and each data represents an $n=3$. $* P<$ $0.05 ;{ }^{*} \mathrm{NS}$. 


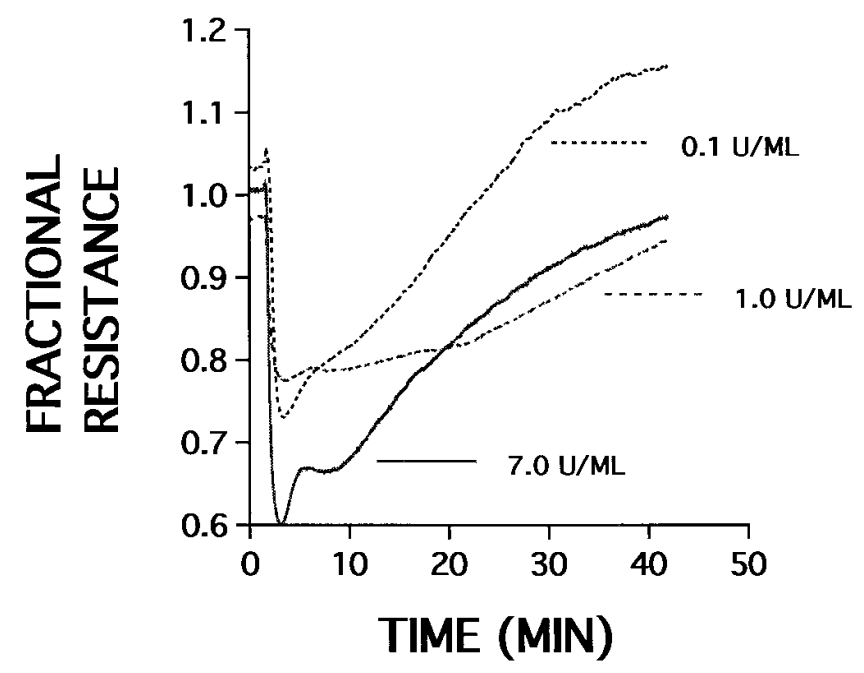

Figure 6. Figure represents the dose-dependent effect of $0.1 \mathrm{U} / \mathrm{ml}$, $1.0 \mathrm{U} / \mathrm{ml}$, and $7 \mathrm{U} / \mathrm{ml}$ thrombin on the fractional resistance. Data are expressed as a the means for each time point. Each data point reflects an $n=4$.

(Table I). The absence of detectable increases in tension did not represent a malfunction of the assay system since subsequent addition of thrombin to the same monolayer increased tension (data not shown). The histamine-stimulated increase in phosphorylation is consistent with our previously reported increases of $0.19 \pm 0.05 \mathrm{mP} / \mathrm{mMLC}$ at $30 \mathrm{~s}, 0.17 \pm 0.04 \mathrm{mP} /$ mMLC at $90 \mathrm{~s}$, and a return to basal levels by $5 \mathrm{~min}$ (1).

Relationship between actin-myosin contraction and focal adhesion. To quantitate focal adhesion we measured the electrical resistance across monolayers that had achieved a steady state resistance on the microelectrode. Thrombin caused a dose-dependent immediate, but transient, decline in the electrical resistance in response to doses of $0.1,1.0$, and $7.0 \mathrm{U} / \mathrm{ml}$ of thrombin (Fig. 6). At $7 \mathrm{U} / \mathrm{ml}$, thrombin decreased the electrical resistance by $50-60 \%$ at $90 \mathrm{~s}$, and required $\sim 60 \mathrm{~min}$ before the resistance returned to basal levels.

To precisely understand how centripetal tension contributes to changes in focal adhesion, we examined the relationship between isometric tension and electrical resistance in monolayers exposed to thrombin and histamine. We observed that changes in electrical resistance did not parallel changes in isometric tension in cells exposed to thrombin. The time course for isometric tension lagged behind changes in electrical resistance in cultured monolayers exposed to thrombin (Fig. 7 A). Thrombin maximally decreased the electrical resistance by $90 \mathrm{~s}$ while full tension development was not achieved until 8-12 min after exposure. At time points when tension was maximally expressed, restoration of electrical resistance was already initiated.

Since ML-7 prevented actin-myosin contraction, we were interested to know if ML-7 would affect the decrease in resistance caused by thrombin. Pretreatment of cells with ML-7 did not prevent the decrease in resistance caused by thrombin (Fig. 7 B).

$10 \mu \mathrm{M}$ histamine immediately, but transiently, disrupted electrical resistance, independent of an increase in isometric tension (Fig. $7 \mathrm{C}$ ). Histamine decreased resistance by $30 \%$ over a 3-5 min period, while tension did not change over the

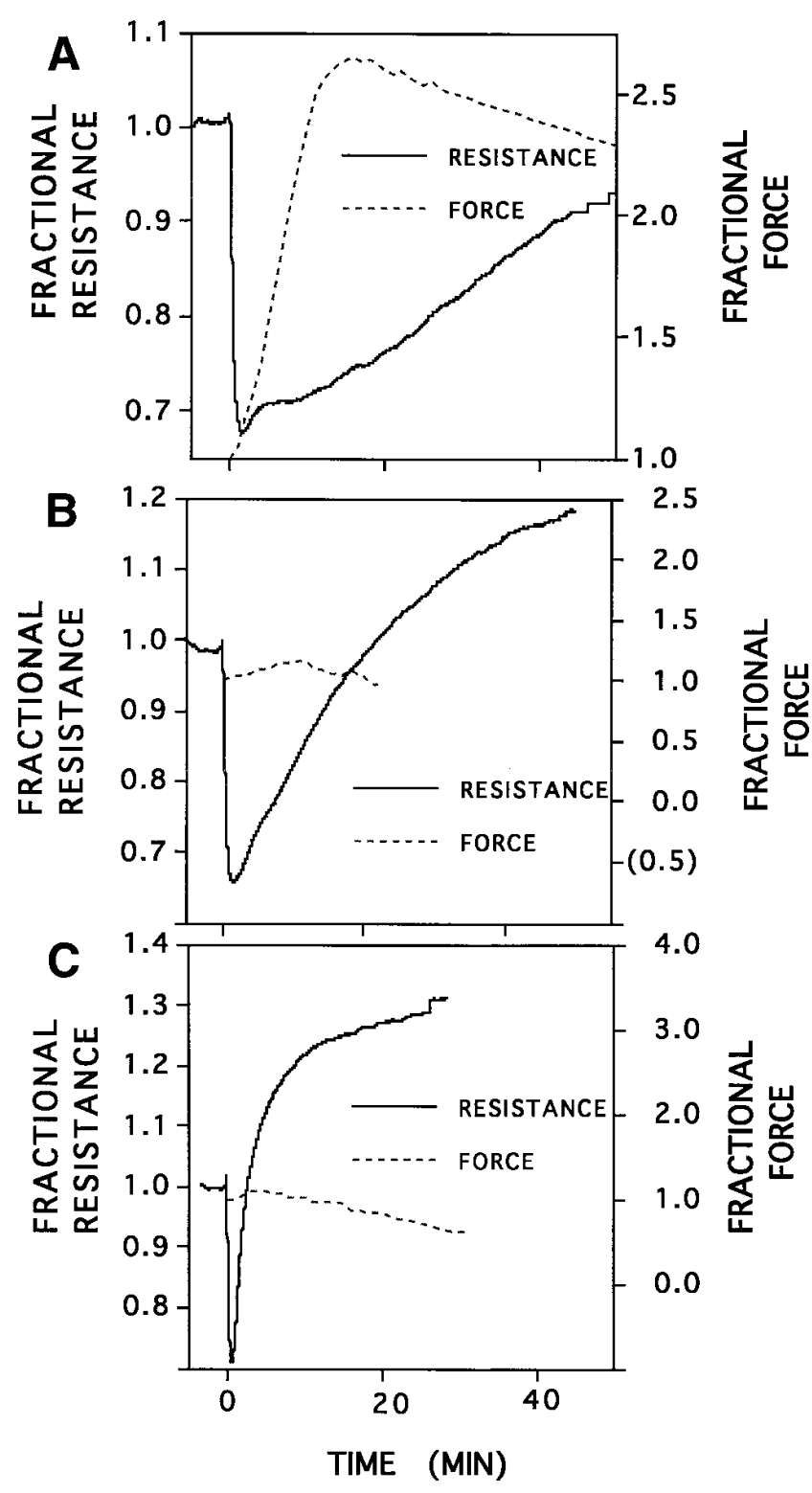

Figure 7. Figure represents the relationship between tension and electrical resistance in response to histamine and thrombin. $(A)$ Represents the relationship between tension and electrical resistance in monolayers exposed to $7 \mathrm{U} / \mathrm{ml}$ of thrombin; $(B)$ represents the relationship between tension and electrical resistance in thrombin-stimulated monolayers pretreated with $100 \mu \mathrm{M}$ ML-7; $(C)$ represents the relationship between isometric tension and electrical resistance in monolayers exposed to $10 \mu \mathrm{M}$ histamine. Isometric tension and the electrical resistance are reported as the means of $\geq 4$ separate experiments. See text for discussion.

same time period. The electrical resistance recovered to basal levels within 3-5 min. Interestingly, histamine caused a subsequent increase in the electrical resistance, indicating an increase in focal adhesion.

Although ML-7 did not prevent the decline in resistance in cells exposed to thrombin, ML-7 did hasten the recovery of electrical resistance in monolayers exposed to thrombin (Fig. 8). The electrical resistance recovered to basal levels within 20 min in thrombin exposed cells pretreated with ML-7, com- 


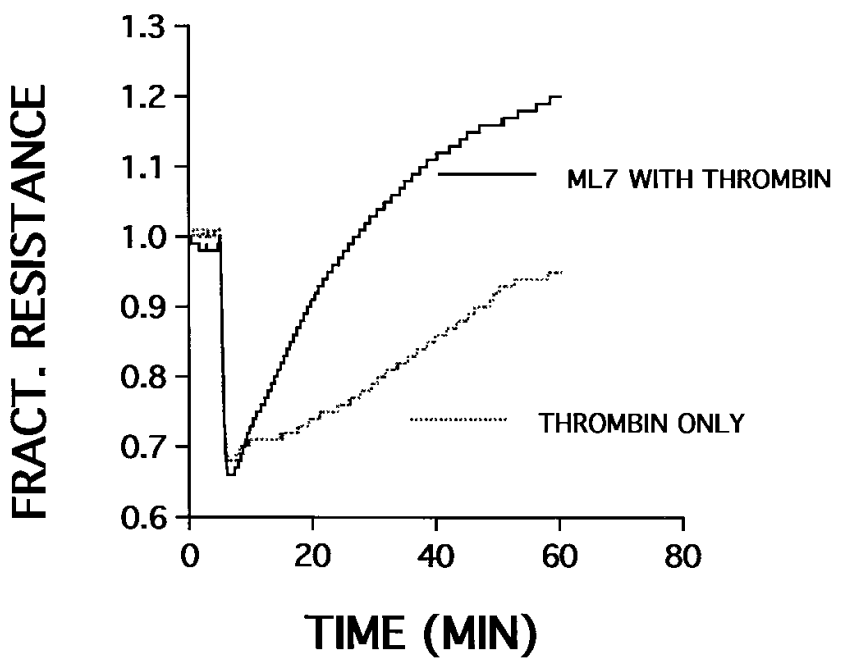

Figure 8. Figure compares the electrical resistance reported as the means between thrombin-stimulated HUVECs treated in the presence and the absence of $100 \mu \mathrm{M}$ ML-7. Each data point represents an $n \geq 5$. See text for explanation.

pared to 45-60 min in cells treated with thrombin alone. Additionally, ML-7 caused the electrical resistance to increase to above basal levels in thrombin-exposed cells. Hence, actinmyosin contraction seemed to delay the restoration of resistance but was not necessary for the initial decrease.

The effects of ML-7 on restoration of electrical resistance were not caused by nonspecific inhibition of other kinases such as protein kinase C. In HUVE cells activation of protein kinase $\mathrm{C}$ with $1 \times 10^{-7} \mathrm{M}$ phorbol 12,13 dibutyrate increased electrical resistance $20 \%$ within $40 \mathrm{~min}$. Hence, inhibition of protein kinase $\mathrm{C}$ would not be likely to restore resistance more rapidly.

\section{Discussion}

Disruption of endothelial focal adhesion is a hallmark of inflammatory edema. Integrin receptor and junctional proteins are coupled to the actin-cytoskeleton so that cytoskeletalbased mechanical forces modulate sites of focal adhesion. We and others have hypothesized that edema formation is determined by a balance between centrifugal forces, forces that tether cells to each other and to the underlying substrate, and centripetal forces, in part, due to actin-myosin tension (1, 7-10, 20-23). However, it is still unknown how edemagenic agents precisely change the relationship between centripetal and centrifugal forces and alter focal adhesion. In this manuscript we demonstrate that histamine and thrombin modulate endothelial focal adhesion through mechanisms dependent and independent of centripetal actin-myosin contraction.

Histamine and thrombin initiated a disruption of focal adhesion independent of centripetal actin-myosin contraction. Histamine caused an immediate but transient decline in electrical resistance in the absence of detectable increased isometric tension. Similarly, thrombin initiated an immediate decline in electrical resistance before full tension development was achieved. More significantly, thrombin decreased the electrical resistance in monolayers pretreated with ML-7, at doses that prevented tension development and prevented an increase in light chain phosphorylation. Hence, histamine and thrombin initiate a decrease in focal adhesion without increasing centripetal tension.

Although the initial disruption of focal adhesion was independent of actin-myosin contraction, centripetal force generated by actin-myosin contraction caused a more sustained decline in electrical resistance. Histamine, which did not increase centripetal tension, decreased resistance for 3-5 min. In contrast, thrombin, which increased tension by $50 \mathrm{mg}$, decreased resistance for 40-60 min. When ML-7 prevented tension development, thrombin decreased the electrical resistance for only $20 \mathrm{~min}$. Hence, expression of centripetal tension prolonged the time until recovery of focal adhesion.

The restoration of focal adhesion in response to histamine and thrombin, especially in the presence of increased centripetal tension, is particularly interesting because it suggests a simultaneous recruitment of centrifugal forces that reseal focal adhesion sites that are disrupted. The presence of activated centrifugal forces is supported by three important observations. First, histamine restored electrical resistance to above basal levels. Second, thrombin initiated restoration of the electrical resistance despite the continued expression of centripetal tension. Third, in cells pretreated with ML-7, thrombin restored electrical resistance to above basal levels. Restoration of endothelial focal adhesion does not appear to occur because of relaxation of actin-myosin tension alone. Instead, recruited centrifugal forces balanced centripetal forces to restore focal adhesion.

Ingber and others have evoked the concept of tensegrity, a balance of continuous series of tensile elements opposed by discontinuous series of compressive-resistive elements, to explain how mechanical cellular forces regulate cell shape (2023). The tensegrity paradigm is determined by the opposing interaction of centripetal mechanical forces generated by microfilaments which are resisted by extracellular forces at points of attachment between adjacent cells and between cells and the underlying substrate. In support of the tensegrity paradigm, previous reports in permeabilized endothelial-cells have demonstrated sustained centripetal cell movement in response to high micromolar levels of calcium and ATP, presumably through actin-myosin contraction $(9,10,24)$. Using this same model, Wysolmerski and Lagunoff demonstrated that microfilament retraction required MLCK and calmodulin, demonstrating that phosphorylation of the $\mathrm{MLC}_{20}$ was required for centripetal tension (9).

Although our results are in agreement with the tensegrity paradigm in which an imbalance between centripetal and centrifugal forces alters focal adhesion, increased centripetal tension does not initiate disruption of focal adhesion. A yet unidentified process initiates disruption of focal adhesion. Unopposed expression of basal centripetal tension, through the primary disruption of calcium-dependent or calcium-independent focal adhesion complexes, could initiate loss of focal adhesion $(8,11,25,26)$. Consistent with this hypothesis, we observed that reduction of $\mathrm{MLC}_{20}$ phosphorylation attenuated cell retraction in response to the breakdown of calcium-dependent adhesion sites (8).

Our in vitro observation that histamine causes a very transitory loss of focal adhesion is supported by in vivo reports (27, 28). In single vessels of rat mesentery, $\mathrm{Wu}$ and Baldwin observed that histamine caused transient gap formation between adjacent cells for 2-5 min (28). These observations support the 
significance of our own observations with cultured cells and the concept of centripetal and centrifugal forces rapidly modulating focal adhesion.

It is important to integrate these observations into effects of these agents on endothelial permeability. A measurement of diffusion or convection of macromolecules across an endothelial monolayer reflects the formation of gaps over time. These gaps need to be open long enough to detect the change in the rate of movement of the marker. Hence, the diffusion represents both the loss of focal adhesion and the rate of its resolution. Molecules that mediate centripetal actin-myosin contraction and sustain a loss of focal adhesion would create greater gap formation over time than molecules that do not contract actin-myosin filaments. Thus, activation of actin-myosin contraction may explain the greater increase in permeability observed with thrombin than with other mediators (29).

We observed that increased isometric tension in HUVE cells in response to thrombin was dependent on MLCK-mediated increases in $\mathrm{MLC}_{20}$ phosphorylation. This is supported by the following evidence: Thrombin increased $\mathrm{MLC}_{20}$ phosphorylation and thrombin increased tension. These events were parallel in time. Thrombin-stimulated increases in $\mathrm{MLC}_{20}$ phosphorylation were mediated by MLCK based on peptide map analysis of phosphorylated tryptic fragments. ML-7, an MLCK inhibitor, inhibited increased MLC $_{20}$ phosphorylation and tension development. These observations are consistent with those of Goeckeler and Wysolmerski which were published while this manuscript was in review (30). They also found that tension development by thrombin stimulated HUVE cells temporally paralleled changes in $\mathrm{MLC}_{20}$ phosphorylation.

The difference in tension developed by histamine and thrombin may be due to differences in the amount of light chain phosphorylation. Histamine increased phosphorylation to $0.44 \mathrm{mP} / \mathrm{mMLC}$ while thrombin increased phosphorylation to over $0.8 \mathrm{mP} / \mathrm{mMLC}$. Myosin light chain phosphorylationdependent granule secretion, smooth muscle contraction, and fibroblast contraction are associated with light chain phosphorylation to $1.0,0.8$, and $0.7 \mathrm{mP} / \mathrm{mMLC}$, respectively $(12,18,31)$. Persechini and Hartshorne demonstrated in vitro that smooth muscle myosin ATPase activity increased exponentially when $\mathrm{MLC}_{20}$ phosphorylation exceeded $0.5 \mathrm{mP} / \mathrm{mMLC}$ (32). They hypothesized that a cooperative interaction between the myosin heads occurs when at least one myosin head is phosphorylated. When we conducted a dose response to thrombin, in the range of doses that caused changes in focal adhesion, we found no differences in phosphorylation or tension. Without a clear dose response to thrombin in terms of phosphorylation and tension it is possible that other signaling events activated by histamine also affect tension development, and our observations might not be indicative of a simple dose response effect of phosphorylation.

In summary, edemagenic agents like histamine and thrombin initiate a disruption of endothelial focal adhesion independent of actin-myosin contraction. Although centripetal actinmyosin contraction did not initiate disruption of focal adhesion, actin-myosin contraction delayed restoration of focal adhesion. These data demonstrate that edemagenic agents modulate endothelial focal adhesion by altering the balance of opposing centripetal and centrifugal forces. Further investigation is needed to identify additional molecular mechanisms that contribute to the forces and how they are regulated.

\section{Acknowledgments}

We would like to thank Jeanne Moy for her assistance on the development of the tension monitor system, and Michael Kolodney and Robert Wysolmerski for their suggestions on the isometric tension system.

This work was supported by the NHLBI Grant HL-33540 (D.M. Shasby) and a research grant from the American Lung Association (A.B. Moy). This work was conducted during Dr. Moy's tenure as a Recipient of the American Heart Association, Clinician Scientist Award and Dr. Shasby's tenure as a Clinical Investigator of the Veterans Administration.

\section{References}

1. Moy, A., B. Scott, S. Shasby, and D.M. Shasby. 1993. The effect of histamine and cyclic adenosine monophosphate on myosin light chain phosphorylation in human umbilical vein endothelial cells. J. Clin. Invest. 92:1198-1206.

2. Laposata, M., D. Dovnarsky, and H. Shin. 1983. Thrombin-induced gap formation in confluent endothelial cell monolayers in vitro. Blood. 62:549-556.

3. Carson, M., S. Shasby, and D.M. Shasby. 1989. Histamine and inositol phosphate accumulation in endothelium: cAMP and G-protein. Am. J. Physiol. 257:L259-L264.

4. Majno, G., and G. Palade. 1961. Studies on inflammation. 1. Effect of histamine and serotonin on vascular permeability: an electron microscopic study. J. Biophys. Biochem. Cytol. 11:571-605.

5. Majno, G., S. Shea, and M. Leventhal. 1969. Endothelial contraction induced by histamine type mediators: an electron microscopic study. J. Cell Biol. 42:647-672.

6. Kolodney, M., and R. Wysolmerski. 1992. Isometric contraction by fibroblasts and endothelial cells in tissue culture: a quantitative study. J. Cell Biol. 117:73-82.

7. Moy, A., R. Sheldon, K. Lindsley, S. Shasby, and D.M. Shasby. 1994. Centripetal tension and endothelial retraction. Chest. 105:107S-108S.

8. Sheldon, R., A. Moy, K. Lindsley, S. Shasby, and D.M. Shasby. 1993. Role of myosin light-chain phosphorylation in endothelial cell retraction. Am. J. Physiol. 265:L606-L612.

9. Wysolmerski, R., and D. Lagunoff. 1990. Involvement of myosin light chain kinase in endothelial cell retraction. Proc. Natl. Acad. Sci. USA. 87:16-20.

10. Wysolmerski, R., and D. Lagunoff. 1991. Regulation of permeabilized endothelial cell retraction by myosin phosphorylation. Am. J. Physiol. 261:C32C40.

11. Pitelka, D., B. Taggart, and S. Hamamoto. 1983. Effects of extracellular calcium depletion on membrane topography and occluding junctions of mammary epithelial cells in culture. J. Cell Biol. 96:613-624.

12. Kolodney, M., and E. Elson. 1993. Correlation of myosin light chain phosphorylation with isometric contraction of fibroblasts. J. Biol. Chem. 268: 23850-23855.

13. Giaever, I., and C.R. Keese. 1984. Monitoring fibroblast behavior in tissue culture with an applied electric field. Proc. Natl. Acad. Sci. USA. 81:37613764 .

14. Giaever, I., and C. Keese. 1986. Use of electric fields to monitor the dynamical aspect of cell behavior in tissue culture. IEEE Transactions on Biomedical Engineering. 33:242-247.

15. Giaever, I., and C.R. Keese. 1991. Micromotion of mammalian cells measured electrically. Proc. Natl. Acad. Sci. USA. 88:7896-7900.

16. Tiruppathi, C., A.B. Malik, P.D. Vecchio, C. Keese, and I. Giaever. 1992. Electrical method for detection of endothelial cell shape change in real time: assessment of endothelial barrier function. Proc. Natl. Acad. Sci. USA. 89: 7919-7923.

17. Ghosh, P., C. Keese, and I. Giaever. 1993. Monitoring electropermeabilization in the plasma membrane of adherent mammalian cells. Biophys. J. 64: 1602-1609.

18. Ludowyke, R., I. Peleg, M. Heaven, and R. Adelstein. 1989. Antigeninduced secretion of histamine and the phosphorylation of myosin by protein kinase C in rat basophilic leukemic cells. J. Biol. Chem. 264:12492-12501.

19. Daniel, J.L., and J.R. Sellers. 1992. Purification and characterization of platelet myosin. Methods Enzymol. 215:78-88.

20. Wang, N., J. Butler, and D. Ingber. 1993. Mechanotransduction across the cell surface and through the cytoskeleton. Science (Wash. DC). 260:11241127.

21. Singhvi, R., A. Kumar, G. Lopez, G. Stephanopoulos, D. Wang, G. Whitesides, and D. Ingber. 1994. Engineering cell shape and function. Science (Wash. DC). 264:696-698.

22. Sims, J., S. Karp, and D. Ingber. 1992. Altering the cellular mechanical force balance results in integrated changes in cell, cytoskeletal and nuclear shape. J. Cell. Sci. 103:1215-1222.

23. Ingber, D. 1993. Cellular tensegrity: defining new rules of biological de- 
sign that govern the cytoskeleton. J. Cell. Sci. 104:613-627.

24. Schnittler, H., A. Wilke, T. Gress, N. Suttorp, and D. Drenckhahn. 1990.

Role of actin and myosin in the control of paracellular permeability in pig, rat and human vascular endothelium. J. Physiol. 431:379-401.

25. Nicolaysen, G. 1971. Intravascular concentrations of calcium and magnesium ions and edema formation in isolated lungs. Acta. Physiol. Scand. 81: 325-339.

26. Shasby, D.M., and S. Shasby. 1986. Effects of calcium on transendothelial albumin transfer and electrical resistance. J. Appl. Physiol. 60:71-79.

27. Curry, F.E., and W.L. Joyner. 1988. Modulation of capillary permeability: methods and measurements in individually perfused mammalian frog microvessels. In Endothelial Cells. Una Ryan, editor. CRC Press Inc., Boca Raton, FL. 1:3-17.

28. Wu, N.Z., and A.L. Baldwin. 1992. Transient venular permeability increase and endothelial gap formation induced by histamine. Am. J. Physiol.
262:H1238-H1247.

29. Schaeffer, R., F. Gong, M. Bitrick, and T. Smith. 1993. Thrombin and bradykinin initiate discrete endothelial solute permeability mechanisms. Am. J. Physiol. 264:H1798-H1809.

30. Goeckeler, Z.M., and R.B. Wysolmerski. 1995. Myosin light chain kinase-regulated endothelial cell contraction: The relationship between isometric tension, actin polymerization, and myosin phosphorylation. J. Cell Biol. 130: 613-627.

31. Silver, P., and J. Stull. 1984. Phosphorylation of myosin light chain and phosphorylase in tracheal smooth muscle in response to KCL and carbachol. Mol. Pharmacol. 25:267-274.

32. Persechini, A., and D. Hartshorne. 1981. Phosphorylation of smooth muscle myosin: evidence for cooperativity between the myosin heads. Science (Wash. DC). 213:1383-1385. 